\title{
Comparison of pelvic floor dysfunction in primiparous and nulliparous women and its relation to pelvic floor muscle strength
}

\author{
Shahida Naghma ${ }^{1 *}$, Achla Batra1, Deepak Kumar² \\ ${ }^{1}$ Department of Obstetrics and Gynecology, ${ }^{2}$ Department of General Surgery, VMMC and Safdarjung Hospital, New
} Delhi, India

Received: 14 May 2020

Accepted: 05 June 2020

*Correspondence:

Dr. Shahida Naghma,

E-mail: shahida_n@yahoo.com

Copyright: ( $)$ the author(s), publisher and licensee Medip Academy. This is an open-access article distributed under the terms of the Creative Commons Attribution Non-Commercial License, which permits unrestricted non-commercial use, distribution, and reproduction in any medium, provided the original work is properly cited.

\section{ABSTRACT}

Background: The pelvic floor muscles (PFM) play an important role in supporting the pelvic and abdominal organs and controlling urinary and fecal continence, in addition to their role in the sexual function. The objective of this study was to compare pelvic floor muscle strength in primiparous 6 months after delivery and nulliparous women, to evaluate pelvic floor dysfunction (PFD) in these women and to find the association of PFD with pelvic floor muscle strength (PFMS).

Methods: A total of 100 women were recruited in the cross-sectional study which included 28 nulliparous and 72 primiparous women 6 months after delivery. The assessment included general physical examination (GPE), POP-Q and assessment of pelvic floor muscle strength by modified oxford score and perineometer.

Results: Endurance of PFMS measured by duration of contraction and number of contractions/min was higher in nulliparous. Mean of the duration of contraction was significantly higher in nulliparous group as compared to primipara i.e., 28.61 seconds and 23.9 seconds in nulliparous and primiparous group respectively $(\mathrm{p}=0.005)$. Mean of the number of contractions performed in one minute was significantly higher in nulliparous group as compared to primipara i.e., 31.04 and 19.97 in nulliparous and primiparous group respectively $(\mathrm{p}<0.0001)$. None of the nulliparous women had any PFD symptoms, while $4.17 \%$ of the primiparous patients had PFD in the form of bladder symptoms and $1.39 \%$ of them had PFD in the form bowel symptoms. Vaginal squeeze pressure was found to be affected by mode of delivery. It was lowest in instrumental delivery. It was $39.78 \pm 13.33 \mathrm{cmH}_{2} 0$ in vaginal delivery, $51.42 \pm 12.88$ $\mathrm{cmH}_{2} \mathrm{O}$ in Caesarean section and $31.67 \pm 14.36 \mathrm{cmH}_{2} \mathrm{O}$ in instrumental delivery (p-0.039).

Conclusions: Endurance of PFMS measured by duration of contraction and number of contractions/min was higher in nulliparous. Vaginal squeeze pressure was found to be affected by mode of delivery. It was lowest in instrumental delivery.

Keywords: Nulliparous, Pelvic floor dysfunction, Pelvic organ prolapse, Primiparous, Urinary incontinence

\section{INTRODUCTION}

The pelvic floor muscles (PFM) play an important role in supporting the pelvic and abdominal organs and controlling urinary and fecal continence, in addition to their role in the sexual function. Pregnancy and childbirth influence this musculature and can decrease their tone, leading to a set of problems known as pelvic floor dysfunction (PFD). ${ }^{1}$ Pelvic floor dysfunction (PFD) is defined as presence of symptoms of urinary incontinence (UI), fecal incontinence (FI), pelvic organ prolapse (POP), sensory or emptying abnormalities of the lower urinary tract, defecation dysfunction, sexual dysfunction (SD) and chronic pain syndromes, which can present separately or coexist. ${ }^{2}$ One of the most important pelvic floor muscle is levator ani. Evidence of the effects of childbirth on levator structure and function is available from clinical research on women with levator ani injury. 
Although the literature is ambiguous, these anatomical changes may lead to symptoms of pelvic floor dysfunction (PFD). ${ }^{3}$

The assessment of pelvic floor muscle strength (PFMS) is important for the prevention, diagnosis and treatment of the pelvic floor dysfunction. The PFMS can be assessed at rest or during activity, by means of resistance and muscular contraction during the gynecological examination, using methods such as: vaginal digital palpation, perineometry, ultrasonography, electromyography, manometry, and vaginal cones. ${ }^{1}$ Many studies have focused on the effects of childbirth on PFM function and symptoms related to their dysfunction. There is scanty literature focusing on comparison of PFM strength in pregnant and non-pregnant women. ${ }^{4-6}$ There are very few studies addressing the changes in levator function after delivery. There is absence of any study with comprehensive evaluation of the symptoms of pelvic floor dysfunction. None of the studies have been conducted on the Indian population. The hypothesis in the present study was that vaginal delivery is associated with functional damage of levator ani resulting in PFD and various intra-natal factors also affect PFMS.

\section{METHODS}

This cross-sectional study was conducted in department of obstetrics and gynecology, VMMC and Safdarjung Hospital, after taking ethical clearance.

A sample of 84 women, 56 primiparous and 28 nulliparous, including $10 \%$ loss to follow up was required, assuming alpha level of significance at $5 \%$, absolute precision of $0.05 \%$ and confidence level $95 \%$. The primiparous subjects (Group A), were recruited from the women coming to well-baby clinic who have delivered at least 6 months back in Safdarjung Hospital. For nulliparous subjects (Group B), married women attending gynecology OPD were recruited. Written informed consent from women participating in study was taken.

Demographic data, medical history, antenatal history, the labor and delivery record such as duration of labor (first and second stage- active and passive), mode of delivery, presence of episiotomy or tear, weight of the baby were recorded in a preset performa. PFD questionnaire (Australian quality of life) was filled. ${ }^{7}$ Score was calculated and recorded. General physical Examination, POP-Q8 and examination for testing pelvic floor strength was done by oxford criteria and recorded in performa. ${ }^{9}$

The PFM was also tested by Urostym ${ }^{\circledR}$ (Laborie) system. The women were informed and taught how to contract the pelvic floor muscles by vaginal palpation. The women were made to lie in a supine position with knees bent and legs slightly apart. A condom was placed over the pressure probe of the measurement device before insertion into the vagina to ensure hygiene for each participant. Abdominal electrodes were used to ensure that the women were contracting only the pelvic floor muscles. The examiner supported the end of the probe manually during the tests.

\section{The PFM function was tested in three ways}

\section{Vaginal squeeze pressure}

It was measured by maximal voluntary contraction (MVC). The women were asked to contact the PFM 3 times as hard as possible and try to hold for 5 seconds. Ten seconds interval was provided between each contraction. The strongest contraction was measured in $\mathrm{cmH}_{2} \mathrm{O}$.

\section{Endurance of PFM contraction}

The women were asked to hold a PFM contraction as long as they could and were not interrupted unless the pressure measurements reached zero or they reported they could not hold the contraction longer. The holding time of the contraction in seconds was used for analysis.

\section{Repeated contractions}

The women were asked to repeat contractions of the PFM continuously, at least 15 times. Number of contractions women could perform, were recorded. Adequate rest (approximately 3-5 minutes) was given between the tests.

For the nulliparous controls, same data collection and examination was done at the time of recruitment.

\section{RESULTS}

Both the groups were similar is respect of age and BMI (Table 1). The PFMS by oxford score was $\geq 3$ in $52 \%$ of nulliparous while only $25 \%$ of women belonging to primiparous group had oxford score $\geq 3$.

Table 1: Demographic distribution of study population.

\begin{tabular}{|llll|}
\hline Parameters & Nullipara & Primiparous & p value \\
\hline Mean age & 24.64 & 22.9 & 0.071 \\
\hline BMI & 23.78 & 23.47 & 0.479 \\
\hline
\end{tabular}

Table 2: Distribution of study population by vaginal squeeze pressure, duration of contraction, and number of contractions.

\begin{tabular}{|llll|}
\hline Parameters & Nullipara & Primipara & p value \\
\hline $\begin{array}{l}\text { Vaginal squeeze } \\
\text { pressure }\end{array}$ & 36.86 & 40.96 & 0.058 \\
\hline $\begin{array}{l}\text { Duration of } \\
\text { contraction }\end{array}$ & 28.61 & 23.9 & 0.005 \\
\hline No. of contractions & 31.04 & 19.97 & $<0.0001$ \\
\hline
\end{tabular}




\section{Vaginal squeeze pressure}

There was a significant difference in squeeze pressure between primipara and nullipara (p-0.028). Mean vaginal squeeze pressure was $36.86 \mathrm{cmH}_{2} \mathrm{O}$ in nulliparous women and $40.96 \mathrm{cmH}_{2} \mathrm{O}$ in primiparous women (Table 2).

Endurance of pelvic floor muscle strength contractions it was lower in primiparous as compared to nulliparous patients.

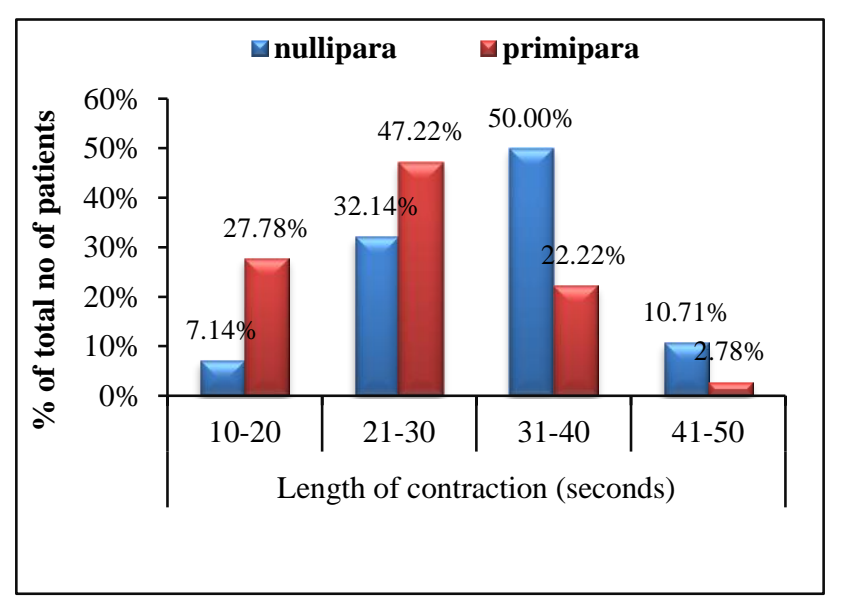

Figure 1: Distribution by duration of contraction.

\section{Duration of contraction}

Mean of the duration of contraction was significantly higher in nulliparous group as compared to primipara i.e. 28.61 seconds and 23.9 seconds in nulliparous and primiparous group respectively $(\mathrm{p}=0.005)$ (Table 2$)$. Majority of the patients in the nulliparous group $(50 \%)$ had length of contraction between 30-39 seconds (Figure 1).

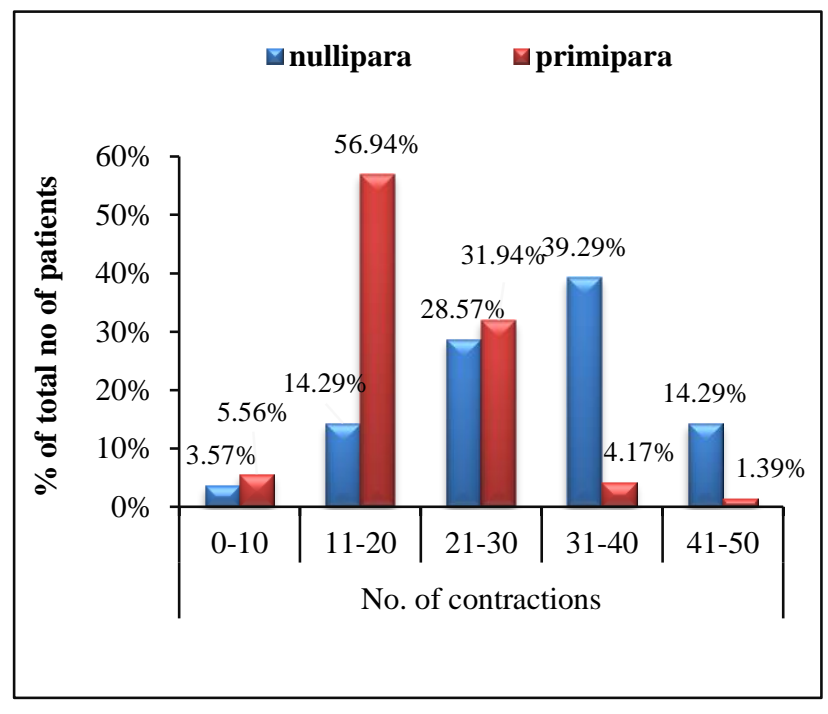

Figure 2: Distribution of number of contractions/minutes.

\section{Number of contractions}

Mean of the number of contractions performed in one minute was significantly higher in nulliparous group as compared to primipara i.e., 31.04 and 19.97 in nulliparous and primiparous group respectively ( $p$ $<0.0001$ ) (Table 2).

Most of the patients in the nulliparous group (39.29\%) could perform contractions in the range of $31-40$, while in the primiparous group most $(56.94 \%)$ could only do it in the range of 11-20 (Figure 2).

Table 3: Mode of delivery and vaginal squeeze pressure, duration of contraction, and number of contractions.

\begin{tabular}{|lllll|}
\hline & Caesarean section & Instrumental delivery & Normal delivery & p value \\
\hline Vaginal squeeze pressure & 51.42 & 31.67 & 39.78 & 0.039 \\
\hline Duration of contraction & 28.21 & 20.08 & 23.59 & 0.089 \\
\hline No. of contractions & 18.21 & 22.25 & 19.91 & 0.410 \\
\hline
\end{tabular}

After instrumental delivery, women had the lowest pelvic floor muscle strength. After caesarean section the strength was not much different from that of nulliparous women, $51.42 \mathrm{cmH}_{2} \mathrm{O}$ and $36.86 \mathrm{cmH}_{2} \mathrm{O}$ respectively.

A significant number of patients who underwent instrumental delivery $(25 \%)$ had a poor vaginal squeeze pressure between 1-20 $\mathrm{cmH}_{2} \mathrm{O}$ compared to $6.52 \%$ of the patients who underwent normal delivery and $0 \%$ of the patients who underwent caesarean delivery ( $\mathrm{p}-0.039)$ (Table 3).

\section{Effect of mode of delivery on PFD}

In the present study, only PFD observed was bladder and bowel dysfunction. None of the patients had prolapse or sexual dysfunction. The PFD was assessed by Australian QOL score and not by the presence of any anatomical defect.

In the primiparous group $(4.17 \%)$ had poor Bladder and bowel QOL and none of the patients in the nulliparous group $(0 \%)$ had any PFD. 
A poor QOL score bowel of $>4$ was present in none of the patients who underwent CS and normal delivery while $8.33 \%$ of the patients who underwent instrumental delivery had a score $>4$. A poor QOL score bladder between 6-8 was present in none of the patients who underwent CS compared to $8.33 \%$ of the patients who underwent instrumental delivery and $4.35 \%$ of the patients who underwent normal delivery.

\section{First and second stage of labour}

Duration of first stage of labor was not found to have an impact on PFMS but second stage was found to have an impact on PFMS. Both strength and endurance were decreased with increased duration of second stage. Mean vaginal squeeze pressure in patients with second stage of labor $<2$ hours were $51.43 \pm 12.88 \mathrm{cmH}_{2} \mathrm{O}$ while it was $38.43 \pm 13.85 \mathrm{cmH}_{2} \mathrm{O}$ in patients with second stage of labor $\geq 2$ hours. Mean duration of contraction in patients with second stage of labor $<2$ hours were 28.21 17.67 seconds and $22.86 \pm 6.12$ seconds in patients with second stage of labor $\geq 2$ hours ( $p-0.048$ ). Mean number of contractions/min in patients with second stage of labor $<2$ hours were $18.21 \pm 4.1$ and $20.93 \pm 6.3$ in patients with second stage of labor $\geq 2$ hours ( $p-0.891$ ). Patients with second stage of labor $\geq 2$ hours had QOL score bladder between 6-8 compared to $0 \%$ of the patients with second stage of labor $<2$ hours. None of the patients with second stage of labor $<2$ hours $(0 \%)$ had a QOL score bowel $>4$ compared to $1.77 \%$ of the patients with seconds stage of labor $\geq 2$ hours (Figure 3 to 5 ).

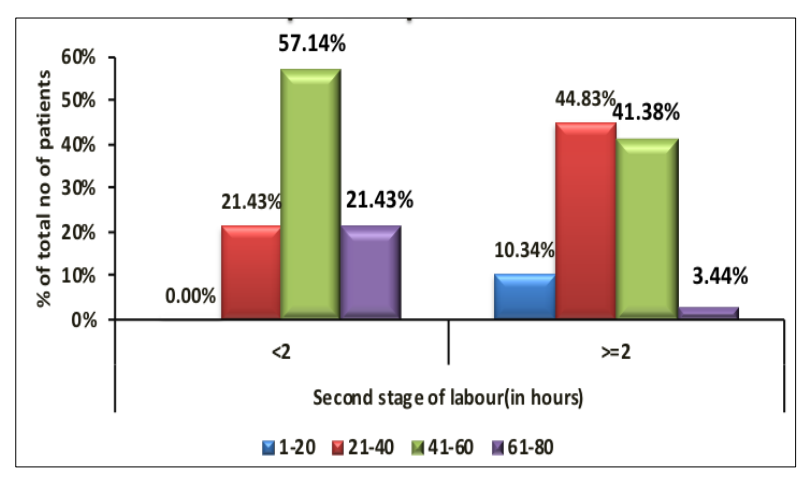

Figures 3: Association of second stage of labour and vaginal squeeze pressure.

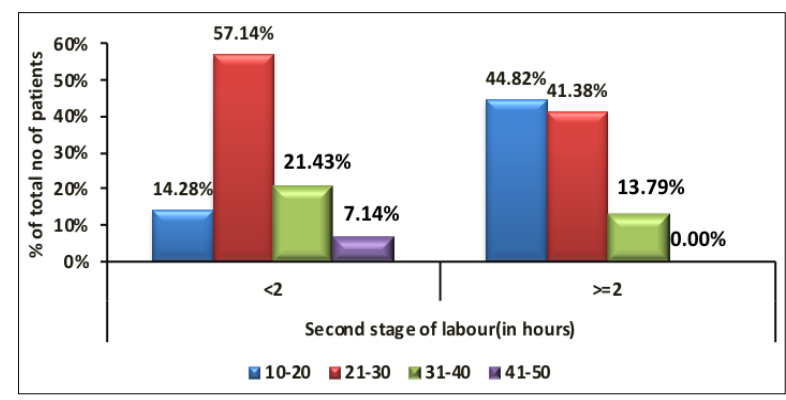

Figure 4: Association of second stage of labour and duration of contraction.

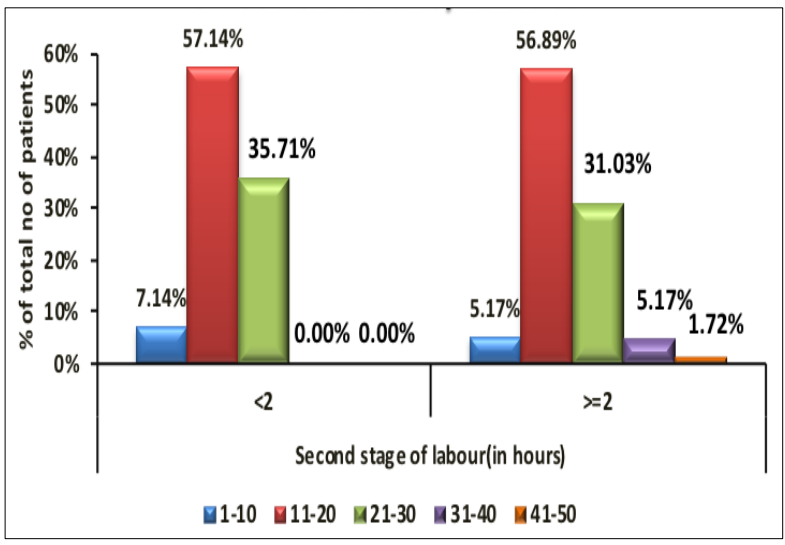

Figure 5: Association of second stage of labour and number of contractions/ minutes.

\section{Effect of tear/episiotomy on PFMS and PFDS}

In this study, there was no affect in strength and endurance by tear/episiotomy.

\section{Birth weight}

Macrosomia with birth weight $>4 \mathrm{~kg}$ is associated with higher incidence of perineal trauma and thus decrease in PFMS and PFD. In the present study any conclusive result could not be obtained on the effect of birth weight on pelvic floor dysfunction as there were no neonates with macrosomia (birthweight $>4 \mathrm{~kg}$ ).

\section{DISCUSSION}

Not many studies have been conducted on the Indian population to study PFMS and PFD. In most western studies the average age of women at time of first delivery is higher. In 4P study and scope study most women were in the age group 30-34 years. ${ }^{2}$ In this study, the two groups were found comparable with respect to age.

\section{Pelvic floor muscle strength (PFMS)}

The present study revealed that there is no difference in PFMS between nulliparous and primiparous women when assessed by manual palpation using modified oxford score.

Resende AP et al, had found statistically significant difference between the MOS score of nulliparous and parous women, 4.5 and 2.1 respectively in the nonpregnant and parous group $(\mathrm{p}=0.005) .{ }^{10}$

In the study by Gameiro MO et al, subjective evaluations of the PFM by oxford scale revealed significant reductions in PFM strength in the primiparous women at the 36 th week and 45 days after delivery compared to the nulliparous women. 52\% of nulliparous had oxford score $\geq 3$ while only $25 \%$ of women belonging to primiparous group had oxford score $\geq 3.9$. 


\section{Vaginal squeeze pressure}

Though it is difficult to compare vaginal squeeze pressure among various studies because of different instruments used however most studies have found lower vaginal squeeze pressure in primiparous compared to nulliparous women. Resende AP et al, had similar findings in their study wherein maximal vaginal contraction (MVC) was significantly greater in the nonpregnant group $(90.7 \mu \mathrm{v})$ than in the pregnant group $(30 \mu \mathrm{v})$, with $\mathrm{p}<0.001$. $^{10}$

Result similar to present study were reported by Afshari et al, who compared pelvic floor strength in nulliparous women and compared them with those after delivery. The mean squeeze pressure was $55.62 \pm 15.86(52.4-58.8) \mathrm{cm}$ $\mathrm{H}_{2} \mathrm{O}$ in nulliparous and was not much different in women who had caesarean or vaginal delivery without episiotomy. ${ }^{11}$

\section{Endurance of pelvic floor muscle strength contractions}

It was measured by maximum duration of contraction and number of contractions over one minute.

\section{Duration of contraction}

Mean of the duration of contraction was significantly lower in primiparous group as compared to nullipara.

\section{Number of contractions}

Mean of the number of contractions performed in one minute was significantly higher in nulliparous group as compared to primipara. Hilde et al in their study followed up nulliparous females from mid-pregnancy to 6 weeks postpartum. They observed that after normal and instrumental vaginal delivery, PFM strength was reduced by $54 \%$ and $66 \%$; and endurance by $53 \%$ and $65 \%$, respectively. Significant differences for all PFM measures $(p<0.001)$ were found when comparing cesarean versus normal and instrumental vaginal delivery, respectively. ${ }^{12}$

\section{Pelvic floor dysfunction (PFD)}

PFD was considered according to Australian QOL score. In the present study none of the nulliparous woman had any PFD. ${ }^{2,13}$ In part of scope study- urinary, fecal, sexual and prolapse were present in a large proportion of nulliparous women. At least one clinically significant symptom was reported by $58.2 \%$ women. $^{2}$ In the epidemiological study by Lukacz et al, $27 \%$ nulliparous women had any PFD. ${ }^{14}$

\section{Various risk factors and their effect on PFMS and development of pelvic floor dysfunction}

Various factors during delivery affect PFMS like mode of delivery, duration of first and second stage of labor, presence of tears/episiotomy, birth weight, etc.

\section{Effect of mode of delivery on PFMS}

Mode of delivery had a significant effect on PFMS with it being lowest in instrumental delivery.

Friedman et al, from their study concluded that in comparison with women who delivered all of their children by cesarean, peak muscle strength and duration of contraction were reduced among women with a history of vaginal delivery (39 compared with $29 \mathrm{cmH}_{2} \mathrm{O}$, $\mathrm{p}<0.001)$. Pelvic muscle strength was further reduced after history of forceps delivery $\left(17 \mathrm{cmH}_{2} \mathrm{O}, \mathrm{p}<0.001\right){ }^{6}$

Meyer et al, did a longitudinal prospective study to compare the effects of forceps delivery and spontaneous delivery on pelvic floor functions. They concluded that patients with forceps delivery have a significantly greater decrease in intra-anal pressure and a greater incidence of a weak pelvic floor (oxford scale score 0-3). The incidence of a weak pelvic floor was $20 \%$ in forceps deliveries $6 \%$ in normal delivery $(\mathrm{p}=0-05) .{ }^{15}$

Contrary to the present study Mendes et al, in their study concluded that the pelvic floor muscle strength does not differ between primiparous women based on the type of delivery. The pelvic floor muscle strength was 24.0 $\mathrm{cmH}_{2} \mathrm{O}( \pm 16.2)$ and $25.4 \mathrm{cmH}_{2} \mathrm{O}( \pm 14.7)$ in postpartum primiparous women after normal birth and caesarean section, respectively, with no significant difference. ${ }^{1}$

\section{Effect of mode of delivery on PFD}

In the present study, only PFD observed was bladder and bowel dysfunction. None of the patients had prolapsed or sexual dysfunction. The PFD was assessed by Australian QOL score and not by the presence of any anatomical defect.

A large cross-sectional study by Rortveit et al, assessing 15,307 women, demonstrated a $10 \%$ risk of any type of UI among women with no history of having given birth. This risk increased to $15.8 \%$ among women with only a history of CS and $24.2 \%$ among women with only a history of VB, resulting in an odds ratio (OR) of 1.7 (1.42.1). ${ }^{16}$

MacLennan et al, reported the following prevalence rates of FI in their cross-sectional study of 1534 women: $1.6 \%$ among women never having given birth, $4.6 \%$ following SVB, $3.9 \%$ following ID, and $4.0 \%$ following CS. ${ }^{17}$

\section{First and second stage of labor}

Duration of first stage of labor was not found to have an impact on PFMS but second stage was found to have an impact on PFMS. Both strength and endurance were decreased with increased duration of second stage.

Many studies have shown that there is injury to pelvic floor at time of vaginal birth which may cause functional 
impairment and longer is the duration of labor more is the extent of damage. ${ }^{18-21}$

Bozkurt $\mathrm{M}$ et al, in their study evaluated various risk factors for development of levator ani muscle injury (LAMI). In the study it was reported that in women who had LAMI confirmed by magnetic resonance imaging, the second stage of labor was 78 minutes longer. ${ }^{18}$

Rogers et al, in their study concluded that VD resulted in prolapse changes and objective UI at 6 months postpartum compared with women who delivered by $\mathrm{CD}$ prior to the second stage of labor. The second stage of labor hence had a modest effect on postpartum pelvic floor function. ${ }^{19}$

In the study conducted by Valsky DV et al, logistic regression showed that second stage duration $\geq 110$ minutes increased odds of LAM trauma by a factor of 5.32. They concluded that prolonged second stage duration is a risk factor in LAM trauma. ${ }^{20}$

\section{Effect of tear/episiotomy on PFMS and PFDS}

Injury to pelvic floor by tear or episiotomy results in decrease in strength and endurance of pelvic floor muscles. However, in this study, there was no affect in strength and endurance by tear/episiotomy.

\section{Birth weight}

Macrosomia with birth weight $>4 \mathrm{~kg}$ is associated with higher incidence of perineal trauma and thus decrease in PFMS and PFD. Phillips $\mathrm{C}$ et al, did a review where in macrosomia was identified as a secondary factor in the development of perineal trauma. ${ }^{22}$ The consequences of this include perineal pain and dyspareunia lasting up to 12 months postnatally. ${ }^{12}$ Mendes EP et al, in their crosssectional study concluded that there was no difference in muscle strength according to newborn weight. ${ }^{1}$

In the present study any conclusive result could not be obtained on the effect of birth weight on pelvic floor dysfunction as there were no neonates with macrosomia (birthweight $>4 \mathrm{~kg}$ ).

The strength of this study was that PFMS was measured objectively by perineometer by a single operator so the values are more reproducible. The limitation was small sample size specially of nulliparous women.

\section{CONCLUSION}

There was no difference in vaginal squeeze pressure between nulliparous and primiparous women. However, endurance was lower in primipara as compared to nullipara.

Normal vaginal delivery did not affect vaginal squeeze pressure or endurance but instrumental delivery was associated with lower vaginal squeeze pressure and endurance.

Pelvic floor dysfunction after delivery is associated with duration of second stage of labor and instrumental delivery. PFMS is decreased after delivery and there is higher level of PFD after delivery, but mode of delivery does not affect the PFMS and PFD. However, there is lower PFMS and higher PFD after instrumental delivery.

\section{Funding: No funding sources \\ Conflict of interest: None declared}

Ethical approval: The study was approved by the Institutional Ethics Committee

\section{REFERENCES}

1. Mendes EP, Oliveira SM, Caroci AS, Francisco AA, Oliveira SG, Silva RL. Pelvic floor muscle strength in primiparous women according to the delivery type: cross-sectional study. Rev Latino-Am Enfermagem. 2016;24:e2758.

2. Durnea C. The impact of first pregnancy and delivery on pelvic floor dysfunction. PhD Thesis, University College Cork. 2014;1:38.

3. Steensma AB, Konstantinovic ML, Burger CW, De Ridder D, Timmerman D, Deprest J. Prevalence of major levator abnormalities in symptomatic patients with an underactive pelvic floor contraction. Int Urogynecol J. 2010;21:861-7.

4. Batista EM, Conde DM, Amaral WN. Comparison of pelvic floor muscle strength between women undergoing vaginal delivery, cesarean section, and nulliparae using a perineometer and digital palpation. Gynecol Endocrinol. 2011;27:910-4.

5. Sigurdardottir T, Steingrimsdottir T, Arnason A, Bo $\mathrm{K}$. Pelvic floor muscle function before and after first childbirth. Int Urogynecol J. 2011;22:1497-503.

6. Friedman S, Blomquist JL, Nugent JM, McDermott KC, Munoz A, Handa VL. Pelvic muscle strength after childbirth. Obstet Gynecol. 2012;120:1021-8.

7. Baessler K, O'Neill SM, Maher CF, Battistutta D. Australian pelvic floor questionnaire: validated interviewer-administered pelvic floor questionnaire for routine clinic and research. Int Urogynecol $\mathbf{J}$ Pelvic Floor Dysfunct. 2009;20:149-58.

8. Bump RC, Mattiasson A, Bo K. The standardization of terminology of female pelvic organ prolapse and pelvic floor dysfunction. Am J Obstet Gynecol. 1996; $175: 13$

9. Gameiro MO, Sousa VO, Gameiro LF, Muchailh RC, Padovani CR, Amaro JL. Comparison of pelvic floor muscle strength evaluations in nulliparous and primiparous women: a prospective study. Clin. 2011;66:1389-93.

10. Resende APM, Petricelli CD, Bernardes BT. Distensibility and strength of the pelvic floor muscles of women in the third trimester of pregnancy. Int Urogynecol J. 2012;23:1041. 
11. Afshari $\mathrm{P}$, Dabagh F, Iravani M, Abedi $\mathrm{P}$. Comparison of pelvic floor muscle strength in nulliparous women and those with normal vaginal delivery and cesarean section. Int Urogynecol J. 2017;28(8):1171-5.

12. Hilde G, Staer-Jensen J, Siafarikas F, Engh ME, Braekken IH, Bo K. Impact of childbirth and mode of delivery on vaginal resting pressure and on pelvic floor muscle strength and endurance. Am J Obstet Gynecol. 2013;208:1-50.

13. Nygaard I, Barber MD, Burgio KL, Kenton K, Meikle S, Schaffer J, et al. Prevalence of symptomatic pelvic floor disorders in US women. JAMA. 2008;300:1311-6.

14. Lukacz ES, Lawrence JM, Contreras R, Nager CW, Luber KM. Parity, mode of delivery, and pelvic floor disorders. Obstet Gynecol. 2006;107:1253-60.

15. Meyer S, Hohlfeld P, Achtari C, Russolo A, De Grandi P. Birth trauma: short and long-term effects of forceps delivery compared with spontaneous delivery on various pelvic floor parameters. BJOG. 2000;107:1360-5.

16. Rortveit G, Daltveit AK, Hannestad YS, Hunskaar S. Norwegian EPINCONT study. Urinary incontinence after vaginal delivery or cesarean section. N Engl J Med. 2003;348(10):900-7.

17. MacLennan AH, Taylor AW, Wilson DH, Wilson D. The prevalence of pelvic floor disorders and their relationship to gender, age, parity and mode of delivery. Obstetr Gynecol Survey. 2001;56:335-6.
18. Bozkurt M, Yumru AE, Sahin L. Pelvic floor dysfunction, and effects of pregnancy and mode of delivery on pelvic floor. Taiwanese $\mathbf{J}$ Obstetr Gynecol. 2014;53:452-8.

19. Rogers RG, Leeman LM, Borders N, Qualls C, Fullilove AM, Teaf D, et al. Contribution of the second stage of labour to pelvic floor dysfunction: a prospective cohort comparison of nulliparous women. Br J Obstet Gynaecol. 2014;121:1145-53.

20. Valsky DV, Lipschuetz M, Bord A, Eldar I, Messing B, Hochner-Celnikier D, et al. Fetal head circumference and length of second stage of labor are risk factors for levator ani muscle injury, diagnosed by 3-dimensional transperineal ultrasound in primiparous women. Am J Obstet Gynecol. 2009;201:1-91.

21. Serati M, Salvatore S, Khullar V, Uccella S, Bertelli E, Ghezzi F, et al. Prospective study to assess risk factors for pelvic floor dysfunction after delivery. Acta Obstet Gynecol Scand. 2008;87:313-8.

22. Phillips C, Monga A. Childbirth and the pelvic floor: The gynaecological consequences. Rev Gynaecol Pract. 2005;5:1-8.

Cite this article as: Naghma S, Batra A, Kumar D. Comparison of pelvic floor dysfunction in primiparous and nulliparous women and its relation to pelvic floor muscle strength. Int J Reprod Contracept Obstet Gynecol 2020;9:3011-7. 